\title{
Percutaneous Muscle Biopsies: Review of 900 Consecutive Cases at London Health Sciences Centre
}

\author{
Kendra L. Derry, Michael N. Nicolle, Julia A. Keith-Rokosh, Robert R. Hammond
}

\begin{abstract}
Objective: In the present study we review our experience with 900 consecutive percutaneous muscle biopsies over the period 1993 to 2007. We examined the advantages and limitations of the procedure, biopsy site preferences, diagnostic range, frequency of diagnoses and quality of histopathology. Demographics, referral patterns and patients' perceptions of the procedure were also assessed. Methods: Cases were identified through the London Health Sciences Centre Department of Pathology database. Standard biopsy procedures were followed using a manual trocar style instrument. With a neuropathology technologist in attendance at all biopsies, biopsies were oriented in the fresh state and snap frozen. Results: Most referrals for muscle biopsy were from neuromuscular neurologists. The procedure was found to be efficient, well-tolerated and produced high quality specimens in all diagnostic categories. No major complications occurred. Failure to obtain an adequate tissue sample, although uncommon $(<2 \%)$, was usually due to marked obesity, edema or muscle wasting. Bleeding at the site was rarely problematic and no wound infections were reported. Conclusions: Needle muscle biopsies represent an efficient alternative to open biopsies when peripheral nerve sampling is not required and when large tissue samples are not needed for extensive biochemical analyses.
\end{abstract}

RÉSUMÉ: Biopsie musculaire percutanée : revue de 900 cas consécutifs au London Health Sciences Centre. Objectif : Nous avons revu notre expérience concernant 900 cas consécutifs de biopsies musculaires percutanées effectuées entre 1993 et 2007 . Nous avons examiné les avantages et les limites de cette intervention, l'endroit choisi pour faire la biopsie, la plage diagnostique, la fréquence des diagnostics et la qualité de l'histopathologie. Nous avons également analysé les données démographiques, les modalités de référence et les perceptions des patients concernant l'intervention. Méthodes : Les cas ont été identifiés au moyen de la base de données du département de pathologie du London Health Sciences Centre. Un trocart manuel a été utilisé et la procédure standard de biopsie a été suivie. Un technicien en neuropathologie était présent au moment de chacune des biopsies et il prenait charge immédiatement du matériel à l'état frais pour le congeler rapidement. Résultats : La plupart des patients référés pour une biopsie musculaire avaient été référés par un neurologue spécialiste des maladies neuromusculaires. L'intervention était efficace, bien tolérée et les spécimens étaient de très bonne qualité, quel que soit le type de pathologie. Aucune complication majeure n'a été observée. L'absence de tissu adéquat, bien que rare $(<2 \%)$, était habituellement due à une obésité importante, à de l'œdème ou à une atrophie musculaire. Un saignement à l'endroit du prélèvement était un problème rare et aucune infection de la plaie n'a été rapportée. Conclusions : La biopsie musculaire à l'aiguille est une alternative efficace à la biopsie ouverte quand une biopsie d'un nerf périphérique n'est pas indiquée et quand on n'a pas besoin de gros échantillons de tissus pour faire des analyses biochimiques poussées.

Can. J. Neurol. Sci. 2009; 36: 201-206

Muscle biopsies are an important tool in the diagnosis and management of neuromuscular disorders ${ }^{1,2}$. The biopsies can be performed open or by percutaneous means. Open biopsy benefits from the opportunity to directly visualize the muscle, which is typically held in a muscle biopsy clamp which in turn facilitates orientation (for histopathological examination) and maintains the fibres in a fixed length optimal for ultrastructural examination. If necessary, larger samples can be obtained with an open biopsy and the opportunity to sample peripheral nerve exists.

Percutaneous (needle) biopsies were likely first performed in the mid 1860's, at which time Charriere and Duchenne described the procedure using a trocar-style instrument ${ }^{3}$. Modern muscle biopsy trocars are similar in design.
Percutaneous biopsies can be quickly arranged and are portable; well-suited to the outpatient clinic or bedside. They are well tolerated, with patients typically reporting a brief, mild to moderate "pressure" discomfort. Complications are rare ${ }^{4-6}$ and

\footnotetext{
From the Department of Pathology (Neuropathology), London Health Sciences Centre, University of Western Ontario, London, Ontario, Canada.

Received January 18, 2008. Final Revisions Submitted October 22, 2008 Correspondence to: Robert R. Hammond, Department of Pathology, London Health Sciences Centre, University Hospital, University of Western Ontario, 339 Windermere Road, London, Ontario, N6A 5A5, Canada.
} 
the patient is able to immediately resume regular activities. Other authors have reported that percutaneous biopsies produce samples of comparable quality to open biopsies, are less traumatic and require few resources ${ }^{4,7-9}$. When performed by someone familiar with the technique, the volume of muscle obtained is rarely insufficient for microscopic analysis ${ }^{4,9,10}$ with no compromise of histological or histochemical features ${ }^{11,12}$.

The present retrospective study was undertaken to examine patient demographics, procedural tendencies and limitations as well as the diagnostic range and quality of this technique in our experience. We also examined the effect of the referral source on patient volumes and diagnostic categories, comparing neuromuscular neurologists with other neurologists and internists. Finally, data from a patient questionnaire was examined to gain a more objective appreciation of the convenience and tolerability of the procedure from the patient's perspective.

\section{Materials ANd Methods}

An electronic search was conducted of the pathology archives at the London Health Sciences Centre (LHSC) for the period between 1993 and 2007. Outpatients were provided with pamphlets describing the nature of the procedure in lay terms. Patients were instructed to stop antiplatelet and anticoagulant medications one week prior to biopsy. Low-dose heparin in inpatients was not suspended provided International Normalized Ratio (INR) values were normal or minimally elevated (up to 1.5) and platelets were in excess of $50 \times 10^{9} / \mathrm{L}$. On the day of the biopsy, the procedure and its risks were reiterated and consent was obtained. The number of individuals performing the procedure over the study period was relatively small (two neuropathologists and four neurologists).

Muscle biopsies at LHSC were performed using manual trocar-style Bergstrom instruments. A $6 \mathrm{~mm}$ bore trocar (Stille, Micrins Inc., Lake Forest, IL, USA) was used for adults, and a 5 $\mathrm{mm}$ trocar for children. The trocars are washed and sterilized by autoclave. The inner canula was sharpened after approximately every ten procedures and each assembly was replaced after approximately ten sharpenings. Muscles were selected for biopsy on the basis of safety, comfort, accessibility and the availability of normative histological data. As such, quadriceps (vastus lateralis), deltoid, biceps brachii, gastrocnemius and tibialis anterior were preferred. The specific choice was then based on clinical examination, aiming for an affected (but not end-stage) muscle free from potential artefact (eg. EMG needle punctures) $)^{13,14}$.

With the patient supine, the selected muscle was palpated with and without contraction to landmark the incision site, aiming for the approximate midpoint of the muscle belly. A sterile field was prepared and 3 to $5 \mathrm{ml}$ of $2 \%$ Xylocaine with epinephrine was instilled into the skin and subcutaneum, avoiding injection into muscle parenchyma. After local anaesthesia was achieved, a $1 \mathrm{~cm}$ incision was made in skin and subcutaneum, taking care to incise parallel to dermal lines. The 2-part trocar was assembled and inserted through the incision with the outer shaft's window obstructed by the inner cutting canula (Figure 1). The trocar was advanced to the epimysial fascia, which presented increased resistance. The epimysium was then punctured with steady pressure. The instrument was advanced another 1 to $2 \mathrm{~cm}$ into muscle parenchyma at which point the inner canula was partially withdrawn to expose the window of the outer shaft. The muscle was manually compressed towards the window. The inner canula was then closed (performing the myotomy), the entire assembly was rotated $180^{\circ}$ and withdrawn. The inner canula was removed for retrieval of the muscle sample with fine forceps. Typically the procedure was repeated for a total of two or three passes via the same fascial puncture, depending upon the quality and volume of sample retrieved. Optimally, $5 \mathrm{~mm}$ diameter cylinders, approximately 5 $\mathrm{mm}$ in length were obtained leading to individual samples of up to approximately $100 \mathrm{mg}$. Pressure was applied to the wound for three to five minutes, skin edges were reapproximated with steristrips and a dry dressing applied. Blood loss during the procedure was minimal $(<5 \mathrm{cc})$ in all but one case requiring prolonged compression and a tensor bandage (the latter patient had been taking "baby aspirin" not realizing that this was indeed aspirin). The procedure typically lasted 30 to 45 minutes, including the time taken for discussion and consent. After the biopsy, patients were reminded verbally and with written instructions to keep the wound clean and dry for four days at which time the dressing and steristrips could be removed. They were also instructed to go about their usual activities yet avoid heavy exertion with the biopsied limb for the same period of time.

\section{Tissue preparation}

Muscle biopsies were oriented in the fresh state without magnification by a neuropathology technologist. After small portions were preserved in glutaraldehyde for ultrastructural examination, all remaining tissue fragments were positioned in Beem capsules (Marivac, cat. no. EE108-2), three-quarters filled with room temperature tissue mounting gel (Tissue-Tek, Hartfield, PA, USA). The muscle fragments were suspended in the gel, just proximal to the conical end of the capsule with the muscle fibres oriented parellel to the long axis of the capsule (Figure 1). The capsule was then sealed and dropped into a small container of liquid nitrogen, snap freezing the biopsy. After transport to the histopathology laboratory, the conical end of the capsule was removed with a razor and the frozen muscle/gel plug extruded with the assistance of a small probe. The frozen plug was then mounted in cross-section in additional gel on a cryostat chuck and sectioned at a thickness of $4 \mu \mathrm{m}$. The muscle tissue was routinely stained and examined by light and electron microscopy.

\section{Patient Questionnaire}

Twenty adult patients biopsied by one of the authors (RH) received identical anonymized and voluntary questionnaires immediately after their biopsy. The questionnaires were distributed and collected by clinic staff over a six month period. The questionnaires asked about the following aspects of the procedure: i) length of time between referral and biopsy, ii) length of time spent in the waiting room on the day of the biopsy, iii) level of discomfort on a scale from 1 (negligible) to 10 (severe), iv) aspects of the biopsy that could be modified for greater patient comfort, and v) aspects of the biopsy that they found most helpful. 

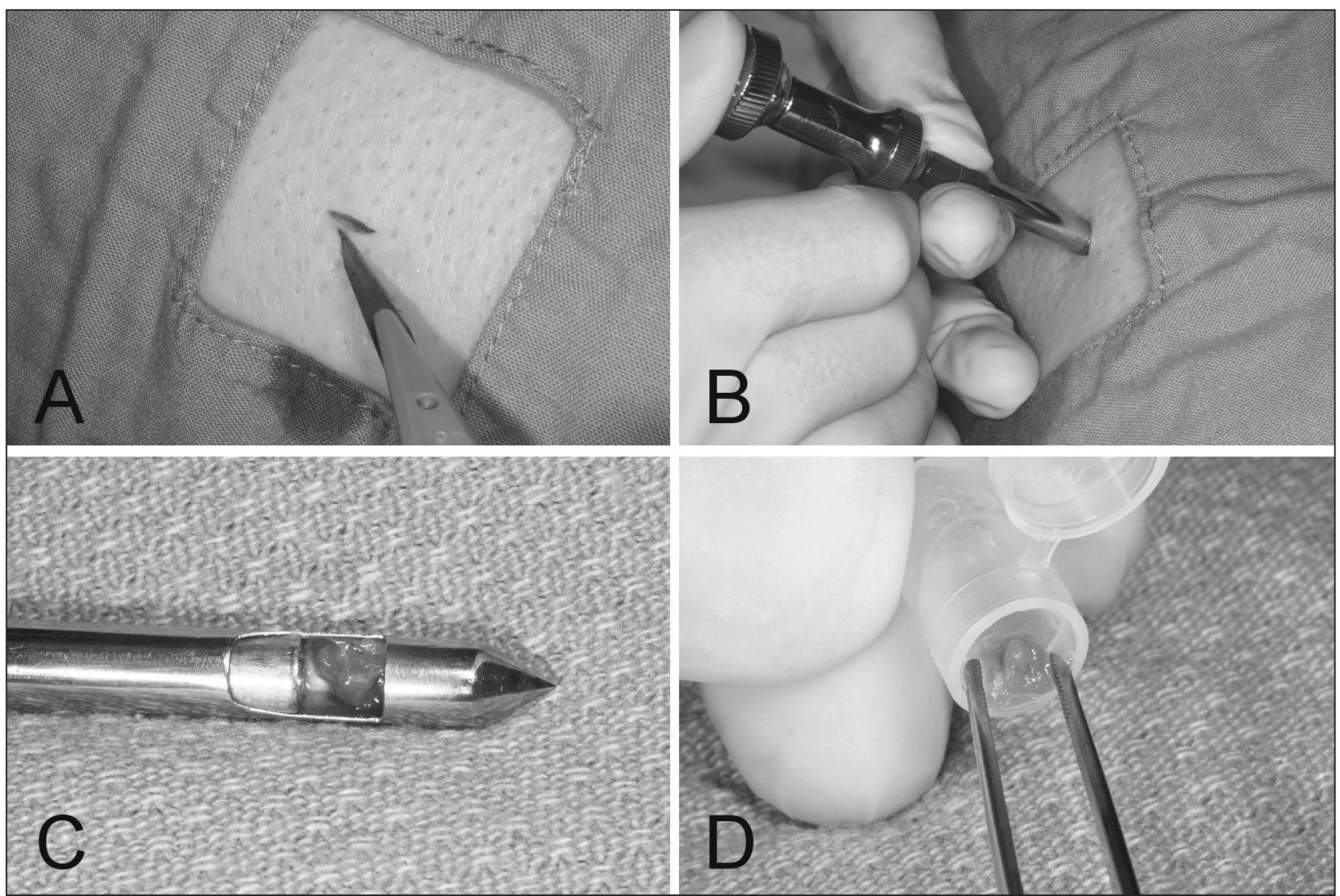

Figure 1: A) After local anaesthesia a $1 \mathrm{~cm}$ skin incision is made, B) the inner and outer shafts are assembled and inserted into the muscle belly and a biopsy is taken. C) The instrument is withdrawn, the inner shaft is retracted and the biopsied tissue retrieved, and D) oriented in a Beem capsule containing tissue mounting gel.

\section{RESULTS}

\section{Patient demographics}

Between 1993 and 2007, 900 percutaneous muscle biopsies were performed on 870 patients; 461 males $(53 \%)$ and 409 females (47\%). Patients ranged in age from 1 to 86 with a median of 51 years (Table 1). All patients were biopsied at LHSC.

\section{Referral Patterns}

In total, 101 physicians referred patients for this procedure. Five LHSC neurologists who specialized in neuromuscular disorders accounted for $62 \%$ of all referrals. In comparing the relative frequency of each diagnostic category between neuromuscular specialists and others, no significant trends were evident (Table 2).

\section{Biopsy site}

Of the 900 biopsies, 677 (75.2\%) were from vastus lateralis and $142(15.8 \%)$ from deltoid. Other muscles sampled included tibialis anterior $(n=33 ; 3.7 \%)$, gastrocnemius $(n=17 ; 1.9 \%)$ and biceps brachii $(\mathrm{n}=5 ; 0.5 \%)$. The biopsy site was not recorded in 26 cases $(2.9 \%)$.

\section{Biopsy Results}

Sixteen $(1.8 \%)$ of the biopsy samples contained insufficient muscle tissue for diagnosis. Severe obesity, edema and cachexia

Table 1: Patient age distribution

\begin{tabular}{lcc}
\hline Age & $\mathbf{n}$ & \% of total \\
$0-10$ & 4 & $0.4 \%$ \\
$11-19$ & 33 & $3.7 \%$ \\
$20-29$ & 85 & $9.5 \%$ \\
$30-39$ & 147 & $16.3 \%$ \\
$40-49$ & 156 & $17.3 \%$ \\
$50-59$ & 167 & $18.6 \%$ \\
$60-69$ & 147 & $16.3 \%$ \\
$70-79$ & 133 & $14.8 \%$ \\
$80-89$ & 28 & $3.1 \%$ \\
\hline
\end{tabular}



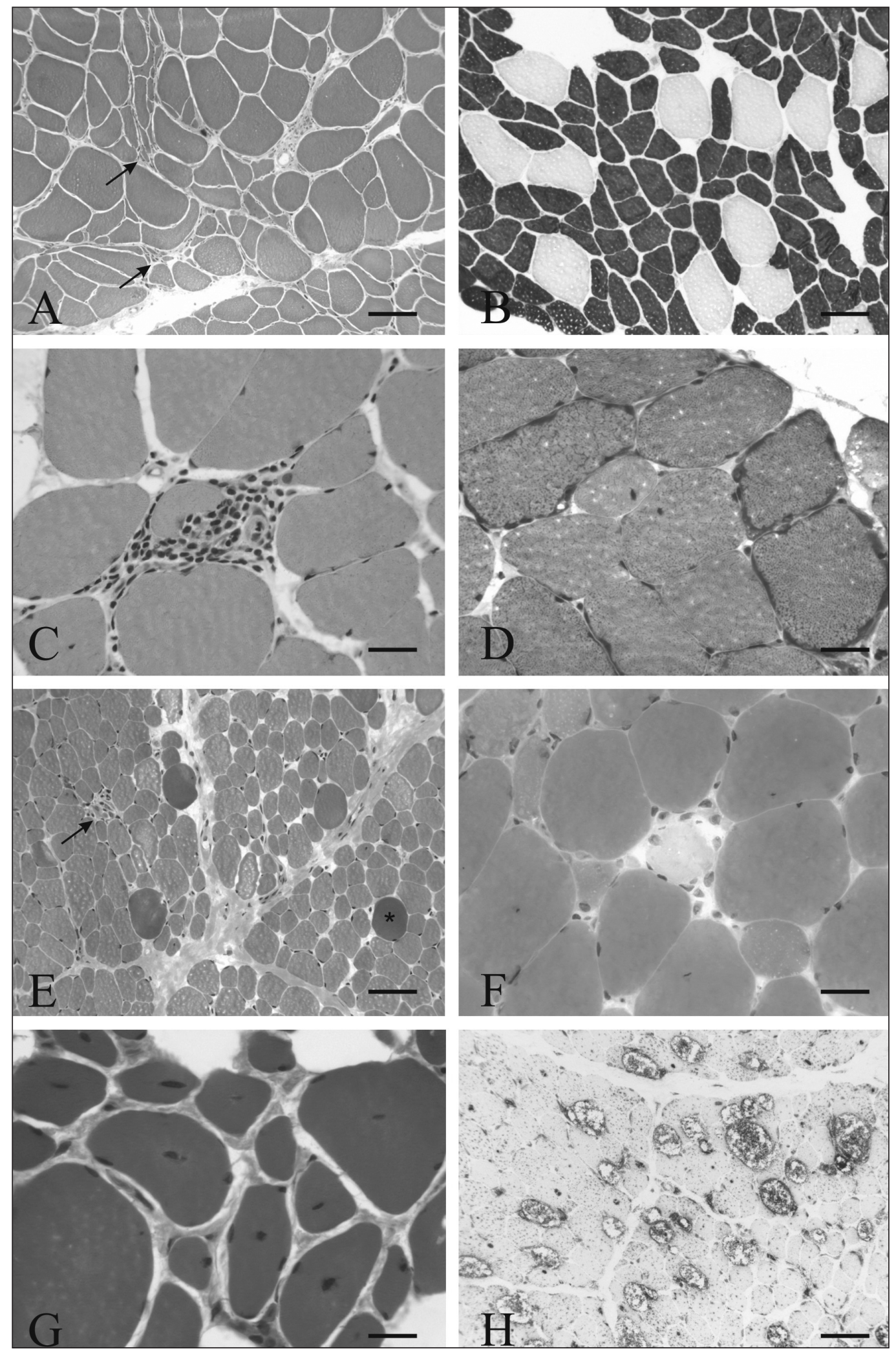

Figure 2: A. Denervation atrophy with grouped angular atrophy (arrows) (Hematoxylin Phloxine Saffron (HPS), bar = 100 um), B. Selective type II fibre atrophy, with type II fibres darkly stained (ATPase pH 9.4, bar = 100 um). C. Polymyositis with a partially invaded non-necrotic fibre centrally in this field of view (HPS, bar = 25 um), D. Mitochondriopathy with ragged red fibres (modified Gomori trichrome, bar $=25$ um), E. Dystrophinopathy revealing fibrosis, fibre degeneration (arrow) and hypercontraction (asterisk) (HPS, bar $=50 \mathrm{um}), \mathrm{F}$. Rhabdomyolysis with a pale, recently lytic fibre centrally in this field of view (HPS, bar $=25 \mathrm{um})$, G. Centronuclear myopathy (HPS, bar $=20 \mathrm{um}), \mathrm{H}$. Acid maltase deficiency displaying increased lysosomal enzyme activity (Acid phosphatase, bar $=50 \mathrm{um}$ ). 
were the most common factors associated with failed biopsies. In a few such cases a subsequent biopsy was successfully guided by ultrasound as described elsewhere ${ }^{8}$. There were 30 repeat biopsies which were carried out for one of the following indications: i) suspected focal / multifocal disease that was not apparent on initial biopsy, ii) nonspecific findings on initial biopsy, iii) additional testing or follow-up of disease progression $^{15}$.

The protocol for rapid freezing and cryoprotection with tissue mounting gel proved to be highly reliable with minimal freezing artefact. In comparison to open biopsies, there was no qualitative difference in histomorphology, histochemistry, immunohistochemistry or ultrastructure. A wide range of diagnostic categories of muscular disease was represented. Broad diagnostic groupings were assembled to give the following case distribution in order of decreasing frequency (Table 2): non-specific myopathic changes $(n=209)$, normal or minor non-specific changes $(n=204)$, denervation $(n=157)$, type II atrophy $(n=95)$, inflammatory myopathies $(\mathrm{n}=90)$, mitochondrial myopathies $(n=45)$, dystrophies $(n=27)$, rhabdomyolysis $(n=21)$, metabolic myopathies $(n=9)$, fibre type disproportion $(n=6)$, vasculitis $(n=5)$, type I atrophy $(n=3)$, other $(n=3)$, nemaline rod $(n=2)$, central core disease $(n=2)$, and centronuclear myopathy $(n=1)$. In a few instances where biopsies were normal or contained minor non-specific changes other diagnoses were ultimately reached through other means, including myasthenia gravis $(n=3)$, malignant hyperthermia $(n=1)$ and periodic paralysis $(n=1)$.

\section{Outpatient Questionnaire}

Eighteen of 20 patients completed and returned the short questionnaire. Thirty-eight percent of respondents waited one month or less for their appointment. Another $39 \%$ waited one to four months and $23 \%$ between four and six months (by contrast, inpatient biopsies were typically arranged and performed within 72 hours). On the day of the biopsy, $76 \%$ of respondents spent 30 minutes or less in the waiting room and none waited more than one hour. The average level of discomfort of the biopsy was 3.9 \pm 2.9 (mean \pm S.D.) which translates into a mild to moderate degree of discomfort. Qualitatively, patients described a sense of ill-defined, deep "pressure" while the biopsy trocar was in place. Subjectively, patients with inflammatory myopathies tended to experience greater discomfort.

All respondents indicated that the thorough explanation of the procedure and the bedside manner of the staff were the most helpful aspects of the procedure. When asked what could be done to improve the experience, no suggestions were made.

\section{Discussion}

Muscle biopsy remains a valuable component of the investigation of neuromuscular disease. Although percutaneous muscle biopsies are routinely carried out at our centre, certain circumstances continue to call for an open procedure. Primary advantages of an open biopsy include the fact that larger samples can be obtained and that peripheral nerves can be biopsied as well.

The percutaneous biopsy is a simple procedure that can be quickly arranged using relatively few resources. It has proven to be a safe and efficient adjunct to the investigation of neuromuscular disorders in the outpatient clinic, on the ward and in the intensive care setting. Percutaneous biopsies are performed solely with local anaesthesia, which may be of further benefit to patients with relative contraindications to general anaesthesia $^{12,13}$.

Table 2: Diagnostic categories and referral patterns

\begin{tabular}{c|c|c|c}
\hline Diagnostic Category & $\mathbf{n}$ & Non-NM MDs & NM subspecialists \\
\hline $\begin{array}{c}\text { Non-specific Myopathic } \\
\text { Changes }\end{array}$ & $209(23.2 \%)$ & $77(22.4 \%)$ & $132(23.7 \%)$ \\
\hline $\begin{array}{c}\text { Normal or Minor Non- } \\
\text { specific Changes }\end{array}$ & $204(22.7 \%)$ & $68(17.8 \%)$ & $136(24.5 \%)$ \\
\hline Denervation & $157(17.4 \%)$ & $60(17.4 \%)$ & $97(17.4 \%)$ \\
\hline Type II Atrophy & $95(10.6 \%)$ & $38(11.0 \%)$ & $57(10.2 \%)$ \\
\hline Inflammatory Myopathy & $90(10 \%)$ & $30(9.6 \%)$ & $60(10.8 \%)$ \\
\hline Mitochondrial Myopathy & $45(5 \%)$ & $22(6.4 \%)$ & $17(3.1 \%)$ \\
\hline Dystrophy & $27(3 \%)$ & $10(2.9 \%)$ & $7(1.2 \%)$ \\
\hline Rhabdomyolysis & $21(2.3 \%)$ & $14(4.1 \%)$ & $5(1.0 \%)$ \\
\hline Metabolic Myopathies & $9(1 \%)$ & $4(1.2 \%)$ & $22(4.0 \%)$ \\
\hline Other & $43(4.8 \%)$ & $21(6.1 \%)$ & $556(100 \%)$ \\
\hline Total & $900(100 \%)$ & $344(100 \%)$ & \\
\hline
\end{tabular}

$\mathrm{NM}=$ neuromuscular 
Although percutaneous muscle biopsies typically retrieve smaller samples than afforded by an open procedure, the technique produces tissue samples of equal quality, not forfeiting histomorphology, ultrastructural morphology or diagnostic range. With respect to patchy or multifocal disease, multiple passes with the trocar permit muscles to be widely sampled by varying the depth and trajectory. As the specimens are frozen within minutes of retrieval, enzyme and antigenic preservation for histochemistry and immunohistochemistry respectively are optimal. In the vast majority of cases (98\%), sufficient sample sizes are obtained with relatively few biopsies repeated on account of inadequate sampling. Nonetheless, several authors have reported on modifications to the technique allowing for suction to be applied to the trocar for retrieval of larger samples ${ }^{16-18}$.

The majority of our patients (62\%) are referred by neuromuscular subspecialists and the vast majority of biopsies are taken from either the vastus lateralis $(75.2 \%)$ or deltoid $(15.8 \%)$. Patients find the procedure efficiently scheduled, well explained and readily tolerable. Furthermore, they are able to resume regular activities immediately post-procedure with no reported wound infections in our experience to date.

In summary, our experience to date with percutaneous muscle biopsies has been very positive on account of the many advantages that they afford, being only limited by the size of sample and the inability to sample peripheral nerve. Given the modest resources and training required, we recommend that the technique be more widely adopted, reserving open muscle biopsies for special circumstances.

\section{ACKNOWLEDGEMENTS}

The authors thank Dr. Mark Tarnopolsky for helpful discussions and recognize Dr. Bill Brown and Dr. David Munoz for initiating the percutaneous muscle biopsy procedure at the London Health Sciences Centre. Similarly, this procedure would not be possible if not facilitated by Karen Mackie, Deb Reade, June Jansen, Debbie Newman, Laurie Fournier and the Departments of Pathology and Clinical Neurological Sciences.

\section{REFERENCES}

1. Gorson KC. Approach to neuromuscular disorders in the intensive care unit. Neurocrit Care. 2005;3(3):195-212.

2. Lee YS. The role of muscle biopsy in the diagnosis of neuromuscular disorders. Ann Acad Med Singapore. 1989 Jul; 18(4):410-5.

3. Charriere M, Duchenne GB. Emporte piece histologique. Bull Acad Med. 1865;30:1050-1.

4. Edwards RH, Round JM, Jones DA. Needle biopsy of skeletal muscle: a review of 10 years experience. Muscle Nerve. 1983 Nov-Dec;6(9):676-83.

5. Magistris MR, Kohler A, Pizzolato G, Morris MA, Baroffio A, Bernheim L, et al. Needle muscle biopsy in the investigation of neuromuscular disorders. Muscle Nerve. 1998 Feb;21(2): 194-200.

6. DiLiberti JH, D'Agostino AN, Cole G. Needle muscle biopsy in infants and children. J Pediatr. 1983 Oct;103(4):566-70.

7. Hayot M, Michaud A, Koechlin C, Caron MA, Leblanc P, Prefaut $\mathrm{C}$, et al. Skeletal muscle microbiopsy: a validation study of a minimally invasive technique. Eur Respir J. 2005 Mar;25(3): 431-40.

8. Boltshauser E, Lang W, Varga E. Experience with percutaneous needle muscle biopsy in pediatrics: alternatives to open biopsy? Schweiz Med Wochenschr. 1986 Mar 29;116(13):396-9.

9. Magistris MR, Kohler A, Pizzolato G, Morris MA, Baroffio A, Bernheim L, et al. Needle muscle biopsy in the investigation of neuromuscular disorders. Muscle Nerve. 1998 Feb;21(2): 194-200.

10. Mubarak SJ, Chambers HG, Wenger DR. Percutaneous muscle biopsy in the diagnosis of neuromuscular disease. J Pediatr Orthop. 1992 Mar-Apr;12(2):191-6.

11. Fukuyama Y, Suzuki Y, Hirayama Y, Harada J, Ohsawa M, Saito K, et al. Percutaneous needle muscle biopsy in the diagnosis of neuromuscular disorders in children. histological, histochemical and electron microscopic studies. Brain Dev. 1981;3(3):277-87.

12. Heckmatt JZ, Moosa A, Hutson C, Maunder-Sewry CA, Dubowitz V. Diagnostic needle muscle biopsy. A practical and reliable alternative to open biopsy. Arch Dis Child. 1984 Jun;59(6): 528-32.

13. Edwards RH, Jackson MJ, Helliwell TR, Clague JE. Muscle biopsy techniques. In: Lane RJM, editor. Hand book of muscle disease. 1st ed. New York: Marcel Dekker; 1996. p. 53-8.

14. Engel WK. Focal myopathic changes produced by electromyographic and hypodermic needles, "Needle Myopathy". Arch Neurol. 1967 May;16(5):509-11.

15. Walsh K, Kaye K, Demaerschalk B, Stewart S, Crukley J, Hammond R. AZT myopathy and HIV-1 polymyositis: one disease or two? Can J Neurol Sci. 2002 Nov;29(4):390-3.

16. Evans WJ, Phinney SD, Young VR. Suction applied to a muscle biopsy maximizes sample size. Med Sci Sports Exerc. 1982; 14(1):101-2.

17. Greig PD, Askanazi J, Kinney JM. Needle biopsy of skeletal muscle using suction. Surg Gynecol Obstet. 1985 May;160(5):466-8.

18. Bourgeois JM, Tarnopolsky MA. Pathology of skeletal muscle in mitochondrial disorders. Mitochondrion. 2004 Sep;4(5-6): $441-52$. 